\title{
Neural Correlates of Risk Perception during Real-Life Risk Communication
}

\author{
Ralf Schmälzle, ${ }^{1}$ Frank Häcker, ${ }^{1}$ Britta Renner, ${ }^{1}$ Christopher J. Honey, ${ }^{2}$ and Harald T. Schupp ${ }^{1}$ \\ ${ }^{1}$ Department of Psychology, University of Konstanz, 78457 Konstanz, Germany, and ${ }^{2}$ Department of Psychology, Princeton University, Princeton, New \\ Jersey 08544
}

During global health crises, such as the recent $\mathrm{H} 1 \mathrm{~N} 1$ pandemic, the mass media provide the public with timely information regarding risk. To obtain new insights into how these messages are received, we measured neural data while participants, who differed in their preexisting H1N1 risk perceptions, viewed a TV report about H1N1. Intersubject correlation (ISC) of neural time courses was used to assess how similarly the brains of viewers responded to the TV report. We found enhanced intersubject correlations among viewers with high-risk perception in the anterior cingulate, a region which classical fMRI studies associated with the appraisal of threatening information. By contrast, neural coupling in sensory-perceptual regions was similar for the high and low H1N1-risk perception groups. These results demonstrate a novel methodology for understanding how real-life health messages are processed in the human brain, with particular emphasis on the role of emotion and differences in risk perceptions.

\section{Introduction}

The fundamental goal of health risk communication is to convey risk-related information to individuals (Glik, 2007; Renner and Schupp, 2011). Especially during new and rapidly spreading global health risks, the mass media play a central role in this endeavor. Through prime-time news bulletins, they can quickly transmit critical information into the homes of millions. However, the effectiveness of such mass-media campaigns may vary across individuals. In particular, differences in perceptions of being at risk, i.e., how susceptible or worried a person feels, have been shown to predict health behaviors and may affect the understanding of risk-related messages (Weinstein, 2003; Renner and Reuter, 2012). Thus, even though the broadcasted information is identical for every recipient, the inherent uncertainty and potential dread associated with risk may trigger varying individual responses and pose challenges for risk communication efforts.

The recent H1N1 pandemic provided a unique opportunity to examine this issue. Here, we report a study in which we used fMRI to track the neural processing of an authentic mass-media broadcast about the H1N1 outbreak. Specifically, based on a screening questionnaire, we identified individuals with either a high or low-risk perception regarding an H1N1 infection. Next, while undergoing fMRI scanning, these individuals were shown an entire TV report about $\mathrm{H} 1 \mathrm{~N} 1$, which aired as a special broadcast on German national

\footnotetext{
Received Nov. 15, 2012; revised May 9, 2013; accepted May 15, 2013.

Author contributions: R.S., B.R., and H.T.S. designed research; R.S. and F.H. performed research; R.S. and C.J.H. contributed unpublished reagents/analytic tools; R.S., B.R., and H.T.S. analyzed data; R.S., F.H., B.R., C.J.H., and H.T.S. wrote the paper.

R.S. was supported by the Lienert Foundation for Biopsychological Research Methods and by the Zukunftskolleg of the University of Konstanz. C.J.H. was supported by NIH Grant R01-MH094480. We thank Uri Hasson for invaluable support. We also thank Tobias Flaisch, Ursula Kirmse, Alexander Barth, Christoph Becker, Martin Imhof, and Felix Schmidt.

Conflict of Interest: The authors declare no competing financial interests.

Correspondence should be addressed to Ralf Schmälzle, Department of Psychology, University of Konstanz, PO Box 36, 78457 Konstanz, Germany. E-mail: Ralf.Schmaelzle@uni-konstanz.de.

DOI:10.1523/JNEUROSCI.5323-12.2013

Copyright $\odot 2013$ the authors $\quad 0270-6474 / 13 / 3310340-08 \$ 15.00 / 0$
}

television. The 30 min long report contained interviews with infected persons, vivid descriptions of catastrophic scenarios, and details on the unpredictable and dramatic spread of the virus.

Our investigation of the neural reception of this authentic TV report about H1N1 builds on recent advances in fMRI research, which show that when different individuals view the same reallife stimulus, neural time courses in many brain regions are strongly correlated across viewers (Hasson et al., 2004, 2010). This intersubject correlation (ISC) approach was adopted for the present study of mass-media risk communication, reasoning that preexisting differences in risk perception might affect the intersubjective similarity of neural processing during the reception of risk-related media messages, particularly in regions coding emotional significance. By contrast, we predicted that sensory-perceptual regions would respond rather homogeneously to the time-varying properties of the report and thus should evince similar correlations across viewers, regardless of preexisting risk perceptions.

\section{Materials and Methods}

\section{Participants and procedure}

Participants were recruited using a two-step procedure. In the first step, participants received a booklet called "NeuroMedia" with the understanding that they would be taking part in a study about the neural processing of audiovisual media. In total, 136 students volunteered to take part in this study. The booklet assessed media habits, attitudes, and perceptions of risk (economic, environmental, food-related risks). To minimize awareness of the goal of our study, the H1N1 risk perceptions items used for prescreening purposes were embedded within these items. The three H1N1 risk perception items were adapted from a previous study (Renner and Reuter, 2012; Brewer et al., 2007; Renner and Schupp, 2011) and assessed worry about becoming infected with H1N1, the absolute perceived likelihood of becoming infected, and the comparative likelihood of contracting the virus compared with an average peer of one's own age and sex. The three items were combined into a standardized H1N1 risk perception score (Cronbach $\alpha=0.78$ ). At the end of the booklet, several questions probed standard criteria for fMRI eligibility. In 


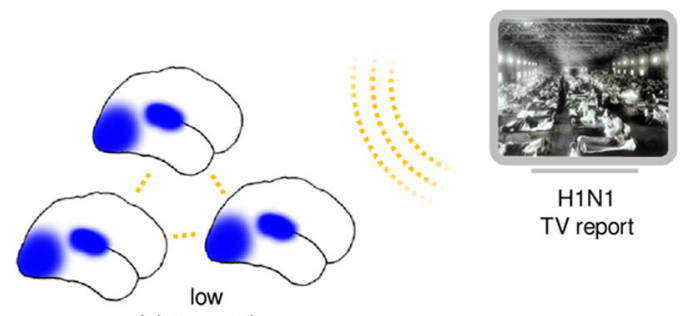

risk perception
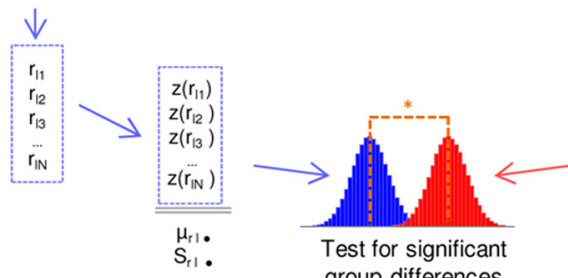
group differences
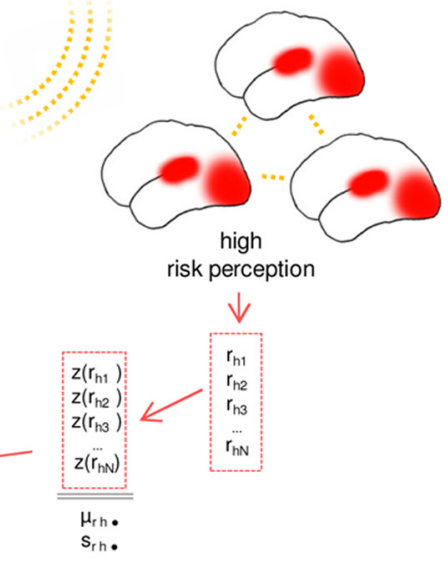

$\downarrow$

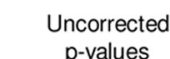

p-values

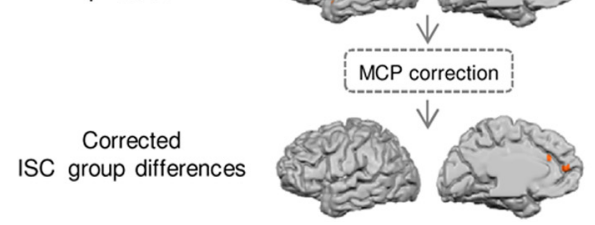

Figure 1. Analysis scheme for intersubject correlation (ISC) group analysis. First, the voxel-by-voxel time courses from every subject within each group are correlated with the averaged time course of all other subjects to obtain ISC maps for each group. Second, to directly compare the strength of ISC across groups, ISC values from the first analysis step are extracted for every viewer and contrasted between groups. Statistical values are then corrected for multiple-comparisons and displayed.

the second step, participants were invited to individual scanning sessions based on the H1N1 risk perception score, starting at both ends of the H1N1 risk perception score distribution. In addition, criteria for fMRI eligibility were checked. Participants arrived at the laboratory with the understanding that the study was investigating neural processes involved during movie watching. They were told that the experimental stimulus would be chosen from several categories (e.g., movie, documentary, and television series).

The final dataset included 24 participants, 12 in each group $(\mathrm{M}=22.85$ years, $\mathrm{SD}=5.7,19$ females). The participants had either high or low perceptions of $\mathrm{H} 1 \mathrm{~N} 1$ risk $\left(p<0.001 ; \mathrm{M}_{\text {high risk }}=10.83 ; \mathrm{SD}=1.58 ; \mathrm{M}_{\text {low risk }}=5.42\right.$; $\mathrm{SD}=1.45)$. Differences in risk perception between groups were specific to H1N1 as there were no differences regarding environmental $(p=1.0)$, nutritional $(p=0.52)$, or economic risks $(p=0.53)$. Participants had normal hearing, normal or corrected-to-normal vision, and provided written informed consent. Five other participants were excluded because of technical problems during stimulation (failure of one or two audio-channels or video equipment) or excessive head movement. Participants received either monetary reimbursement or course credit for their participation. Procedures were in compliance with the safety guidelines for MR research and were approved by the local ethics committee.

\section{MRI acquisition}

Experimental participants with either low or high H1N1-risk perceptions were invited to the scanning facility and scanned on an individual basis while viewing the same audiovisual H1N1 report. Scanning took place in a 1.5 T Philips Intera MR System equipped with Power Gradients. Blood oxygenation level-dependent (BOLD) contrast was acquired using a T2* weighted Fast Field Echo-Echo Planar Imaging (FFE EPI) sequence using parallel scanning technique (Pruessmann et al., 1999). In plane resolution of the axially acquired slices was $3 \times 3 \mathrm{~mm}$ and the slice thickness was $3.5 \mathrm{~mm}$ (32 slices; no gap; $\mathrm{FOV}=240 \mathrm{~mm}$; acquisition matrix: $80 \times 80$ voxels; $\mathrm{TE}=$ $40 \mathrm{~ms}$; flip angle $=90^{\circ}$ ). A TR of $2500 \mathrm{~ms}$ was used throughout the experiment, which consisted of the acquisition of 793 functional volumes $(33 \mathrm{~min}$, 205 volumes for the control stimulus). In addition, a T1-weighted high res- risk perception

olution anatomical scan was obtained for each participant $(\mathrm{T} 1 \mathrm{TFE} ; \mathrm{FOV}=256 \times 256 \mathrm{~mm}$; 200 sagittal slices; voxel size $=1 \times 1 \times 1$ $\mathrm{mm})$. The visual stimulus was delivered through MR-compatible video goggles (VisualSystem, NordicNeuroLab) and the corresponding soundtrack through headphones (MR Confon $\mathrm{GmbH}$ ).

\section{Stimuli and experimental design}

The main stimulus was a 30 min long TV documentary that aired on German national television in October 2009. The documentary contained a wealth of information about H1N1, but also held up an atmosphere of suspense and ominous uncertainty. For instance, it started with a depiction of empty subways, soccer stadiums, and public places. The soundtrack contained dramatic artificial music and a commentator uttered concern that all public life may cease as a result of a catastrophic $\mathrm{H} 1 \mathrm{~N} 1$ pandemic. It then covered the origin and the biological mechanisms of $\mathrm{H} 1 \mathrm{~N} 1$ and presented scenarios of the possible near future. Experts from politics and antivirus protection services were interviewed. Subplots dealt with the economic aspects of the epidemic, the severe disruptions in international plane travel, the discussion about whether governments should purchase vaccines, and about the role played by the pharmaceutical industry. A historical excursion shed light on the fatal consequences of the Spanish Flu of 1918, showing images from sick bays with many victims. In sum, the documentary was typical for the type of media reports at that time, providing a mixture of information and sensationalism. Immediately after the scanning session, participants answered comprehension questions, which revealed that all participants were able to report on the basic content of the report. A control stimulus unrelated to H1N1 was also presented. This was a TV documentary about astronomy that lasted $8 \mathrm{~min}$. It contained astronomical images and interviews with hobby astronomers. Participants reported that they had not seen the stimuli before the experiment.

\section{FMRI preprocessing}

Data analysis was performed using the Brainvoyager QX software package (BrainInnovation) for preprocessing and complementary in-house software written in MATLAB (MathWorks). Preprocessing of functional scans included slice time correction, realignment, and normalization into a shared Talairach coordinate system (Talairach and Tournoux, 1988). To further overcome misregistration across subjects, the data were spatially smoothed with a Gaussian filter of 6 $\mathrm{mm}$ full-width at half-maximum value. Linear trends were removed from the data and low frequencies (e.g., slow drift) were filtered out with up to six cycles per experiment. To eliminate onset transients and horizon effects, the first 16 and last 5 recorded time points were discarded.

\section{Intersubject correlation analysis}

To analyze neural data recorded during viewing of the authentic H1N1 documentary, we adopted the ISC approach (Hasson, et al., 2010), which allows researchers to employ fully naturalistic stimuli. ISC assesses the voxel-by-voxel correlations between fMRI time courses from different individuals. Because all viewers are exposed to the identical material, which serves as its own control, ISC result maps provide a measure of the intersubjective similarity of continuous neural processing at the level of individual brain regions.

A two-step analysis scheme (Fig. 1) was adopted to map out regions that showed intersubjectively reliable responses during viewing of the H1N1 documentary: 
In the first analysis step, we examined which regions showed reliably correlated responses within each risk perception group (withingroup ISC analysis). Correlations were computed between the response time courses in each subject against the average time course of the rest of the group on a voxel-by-voxel basis (Hasson et al., 2009a; Honey et al., 2012). We then calculated the average correlation coefficient $(r)$ per voxel, after applying the Fisher Z-transformation to the individual coefficients. Statistical significance for these coefficients was computed using a bootstrapping procedure: for every empirical time course in every voxel, 1000 bootstrap time series were generated using a phase randomization procedure, and empirical $r$ values were then compared against the-null distribution. This basic procedure was performed for all participants with a low H1N1 risk perception ("within lows") and for all participants with a high H1N1 risk perception ("within highs") separately. This analysis stream yielded two maps indexing reliable time courses across subjects within each group. Within-subject group ISC effects are usually widespread (Hasson et al., 2004). Thus, to reveal robust ISC effects, conservative correction for multiple-comparisons [false discovery rate procedure (FDR) with $q=1 \mathrm{e}-7$ ] (Benjamini and Hochberg, 1995) and a 10voxel contiguity threshold were used to create the maps displayed in Figure 2.

In the second analysis step, we extracted the individual subjects' correlation values from the first analyses. For each voxel, we obtained two vectors representing the correlation between each group member and the rest of the group (i.e., one ISC-vector for low and one for high H1N1 risk participants). On a voxel-by-voxel level, these vectors were Fisher Z-transformed and compared via a two-sided two-sample $t$ test to reveal voxels exhibiting significant between-group ISC differences (between-group ISC analysis). As in previous research (cf. Cantlon and Li, 2013), between-subject ISC effects were determined using FDR ( $q=0.05,10$ voxels extent) to correct for multiplecomparisons. The main findings were also observed, albeit with reduced spatial extent, when applying FWE correction.

\section{Nonparametric ISC group comparison}

For nonparametric permutation tests, we randomly divided viewers into two groups and calculated group wise ISC on the mean time course data from each of four regions of interest (ROI, see below). This procedure was executed 1000 times, creating a random distribution of group-ISC differences. The veridical differences between group-ISC-values (obtained from the main analysis) were then compared against this random distribution to determine statistical significance. This analysis was computed at the whole-brain level and for each of four ROIs, which were defined based on the ISC group comparison ( pgACC, adMCC, the sole regions that differentiated high and low risk groups; see Results) and two regions associated with processing auditory and visual properties, which were defined as follows:

Auditory regions. Absolute sound power (200-5000 Hz) values were extracted from the control stimulus (Mukamel et al., 2005; Brennan et al., 2011), which served as an independent "naturalistic localizer." Results were subsampled to $0.4 \mathrm{~Hz}$, to match the sampling rate of our measurements, and then convolved with a hemodynamic response function (Boynton, et al., 1996), and used as a predictor in a random-effects analysis. Regions correlated to changes in sound power were located in the left and right superior temporal gyrus (STG) in the expected vicinity of early auditory cortices.

Visual regions. To approximate the global amount of visual motion, we assessed the variance in pixel values between successive movie frames of the control movie (cf. Bartels, et al., 2008). Using the procedures described above, we identified occipital clusters in left and right middle occipital gyri, respectively.

\section{Identification of large-scale functional networks by seed-based connectivity analysis}

In addition to ISC analysis, a seed-based correlation analysis was used to identify well known functional connectivity networks for vision, audition, as well as higher integrative networks related to default-mode, dorsal attention, executive control, and salience processing. Seed region coordinates were derived from previous studies: for the visual network, the calcarine sulcus [(CS) $x= \pm 7, y=-83, z=2$ ] (Raichle, 2011); for the auditory network, the STG $(x= \pm 51, y=-21, z=9)$ (Burton et al., 2012); for the default-mode network, the posterior cingulate cortex [(PCC) $x=0, y=-52, z=27$ ] (Raichle, 2011); for the dorsal attention network, the posterior intraparietal sulcus [(IPS) $x= \pm 26, y=-66, z=$ 48] (Raichle, 2011); for the executive control network, the dorsolateral prefrontal cortex [(DLPFC) $x= \pm 43, y=36, z=21$ ] (Seeley et al., 2007); finally, for the salience network, the anterior insula [(AI) $x= \pm 29, y=$ 19, $z=1$ ] (Vincent et al., 2008). Where needed, the Yale Nonlinear MNI2Talairach conversion was used to transform MNI coordinates into Talairach space (Lacadie et al., 2008). Seed time courses were extracted from these regions (5 $\mathrm{mm}$ sphere radius) and group-level connectivity maps were obtained via random-effects analysis. The resulting maps were FDR corrected, smoothed, and result maps for bilateral seed regions were collapsed across hemispheres (cf. Vincent et al., 2008).

\section{Significant ISC within groups}

\section{- high $\mathrm{H} 1 \mathrm{~N} 1$ risk \\ - low H1N1 risk}
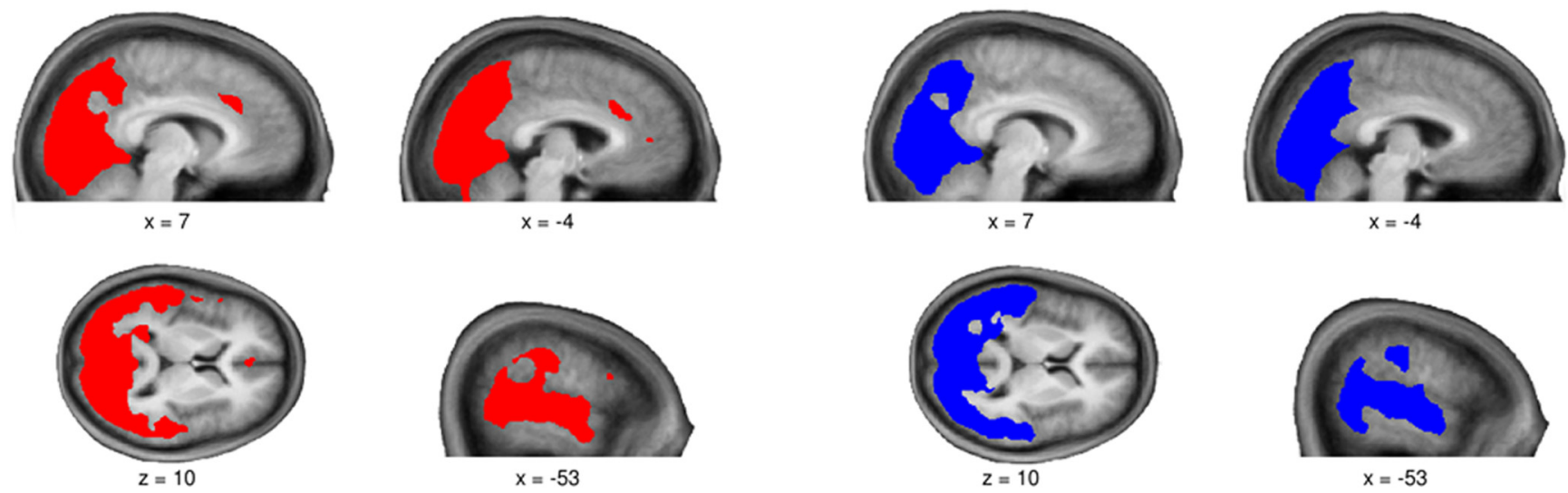

Figure 2. Reliable brain responses within each risk perception group. ISCs among participants with high (red) and low (blue) H1N1 risk perception. The overlap of both analyses is shown in purple. Both maps reveal significantly correlated neural responses in widespread brain regions, extending far beyond primary sensory representation areas into higher-order cortex. Data are FDR corrected and presented on the averaged structural MRI. 


\section{Results}

\section{Within-group ISC analysis}

As shown in Figure 2, both low and high H1N1-risk perception groups showed substantial and significant intersubjective correlations of spatiotemporal brain activity patterns in widespread posterior regions devoted to sensory, perceptual, and semantic processing of the $\mathrm{H} 1 \mathrm{~N} 1$ documentary (Mesulam, 1998). Importantly, group differences were suggested in postperceptual brain regions known to respond to emotional significance. Specifically, the high $\mathrm{H} 1 \mathrm{~N} 1$ risk group showed intersubject correlations in the anterior cingulate cortex [(ACC) Fig. 2].

\section{Between-group ISC analysis}

As shown in Figure 3, although there were no group effects over posterior brain regions, significant group differences emerged for ACC regions. A first cluster emerged in the pregenual anterior cingulate cortex (pgACC; Talairach coordinates $x=-2, y=38, z=10$; cluster size 432 $\mathrm{mm}^{3}$; maximal $\left.t_{(22)}=9.12\right)$ and a second cluster emerged at the border of the pgACC and the pregenual anterior-dorsal midcingulate cortex (adMCC; Talairach coordinates $x=10, y=28, z=31$; cluster size $486 \mathrm{~mm}^{3}$; maximal $t_{(22)}$ $=8.42$ ), extending laterally into the right medial frontal gyrus. Follow-up analyses scrutinized these group differences by conducting more conservative nonparametric permutation tests. As illustrated in Figure $3 B$, the nonparametric analysis revealed significant group differences in neural alignment in the ACC. Furthermore, there was a substantial overlap in findings between parametric and nonparametric analysis. Thus, two different streams of analysis indicate the increased neural coupling in regions of the pgACC and adMCC for high compared with low $\mathrm{H} 1 \mathrm{~N} 1$ risk groups. As elaborated in the discussion, animal electrophysiology and human fMRI studies have linked these regions to psychological processes, such as the evaluation of personal significance, emotional responses, and threat appraisal (Paus, 2001; Vogt et al., 2004; Schmitz and Johnson, 2007; Etkin et al., 2011; Shackman et al., 2011).

\section{ISC group differences across time}

The goal of this analysis was to examine the robustness of our findings at a finer temporal resolution. Thus, the movie was divided into temporal quartiles and the nonparametric permutation ROI analyses were applied for each quartile separately. ROIs included the pgACC and adMCC as defined by the ISC group comparison and two control regions in visual and auditory areas that correlated with sensory features (see Materials and Methods). Comparing the results for the whole epoch (Fig. $4 A$ ) with the quartile analysis (Fig. 4B) confirmed the stability of ACC-ISC increases for viewers with a high $\mathrm{H} 1 \mathrm{~N} 1$ risk perception across time (with the only exception that significance is only approached in the last quartile in the pgACC). In contrast to the ACC, there were no significant group ISC differences for sensory regions in any quartile.

\section{Mean shifts in amplitude of the BOLD signal}

In contrast to classical fMRI activation studies, the ISC approach focuses on extended temporal response patterns and assesses their reliability between subjects. These patterns, however, consist of an ordered series of activations (amplitude peaks). There is therefore the possibility that the significant group differences in neural correlations are secondary to differences in response amplitude between low and high risk groups, e.g., if the low-risk group shows minimal signal variations or if the high risk group shows stronger activations in respective regions. Due to our use of continuous audio-visual movie stimuli, we cannot directly assess changes in response amplitude relative to a blank baseline. Instead, we quantified response amplitudes by computing the SD of the BOLD responses over time after initial transformation to percentage signal change-values centered around the mean (Nir et al., 2006; Samanez-Larkin et al., 2010; Garrett et al., 2011; Lerner et al., 2011) ("dynamic range"). The dynamic range of activity was examined in the two ACC regions and in the auditory and visual regions defined above. Comparison of the dynamic range of the signal between groups revealed no group differences, neither in selected ROIs (Fig. 4C), nor at a corrected whole-brain level (Fig. $4 C$; r-MOG: $\mathrm{M}_{\text {low-risk }}=0.46, \mathrm{SD}=0.1 ; \mathrm{M}_{\text {high-risk }}=$ $0.41, \mathrm{SD}=0.09 ; p=0.18 ; 1-\mathrm{MOG}: \mathrm{M}_{\text {low-risk }}=0.69, \mathrm{SD}=0.18$; $\mathrm{M}_{\text {high-risk }}=0.72, \mathrm{SD}=0.24 ; p=0.71 ; \mathrm{r}-\mathrm{STG}: \mathrm{M}_{\text {low-risk }}=0.4$, $\mathrm{SD}=0.08 ; \mathrm{M}_{\text {high-risk }}=0.44, \mathrm{SD}=0.07 ; p=0.23 ; 1-\mathrm{STG}: \mathrm{M}_{\text {low-risk }}=$ $0.31, \mathrm{SD}=0.06 ; \mathrm{M}_{\text {high-risk }}=0.32, \mathrm{SD}=0.06 ; p=0.63$; adMCC: $\mathrm{M}_{\text {low-risk }}=0.36, \mathrm{SD}=0.07 ; \mathrm{M}_{\text {high-risk }}=0.38, \mathrm{SD}=0.09 ; p=0.44$; pgACC: $\mathrm{M}_{\text {low-risk }}=0.36, \mathrm{SD}=0.06 ; \mathrm{M}_{\text {high-risk }}=0.4, \mathrm{SD}=0.07 ; p=$ $0.16)$. In sum, these results suggest that both groups evince strong response amplitudes. However, temporal coherence across individuals appears to be lower in the low H1N1 risk perception group, whereas responses across individuals with a high H1N1 risk perception are collectively better aligned.

\section{ISC during a control movie}

The reported analyses reveal that the neural processing of H1N1related messages is subject to group differences on the basis of preexisting H1N1 risk perception. However, to argue that the group differences are specific to the processing of risk information demands an additional control condition in which participants receive 


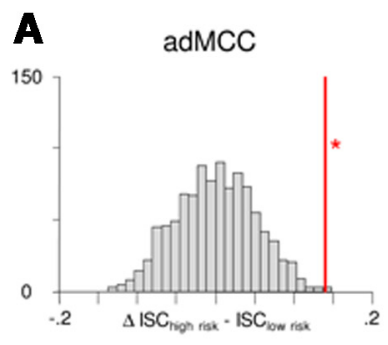

\section{Nonparametric group permutation results}
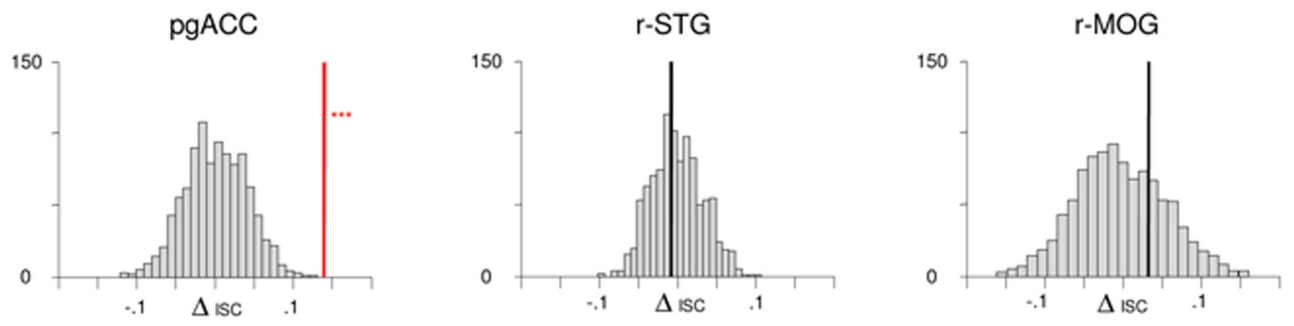

Nonparametric group permutation at finer time scale

B

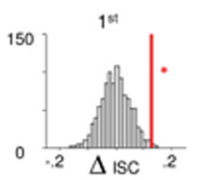

C

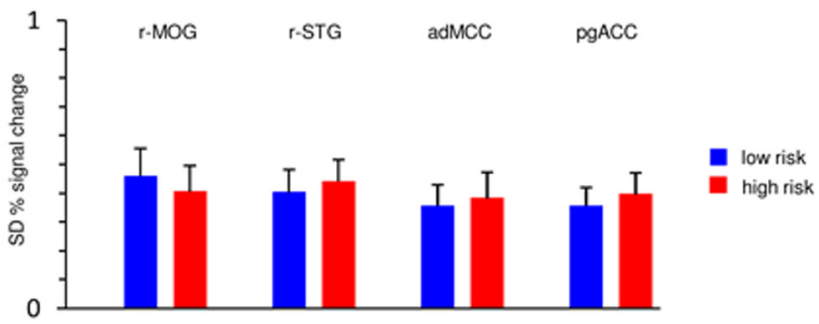

adMCC
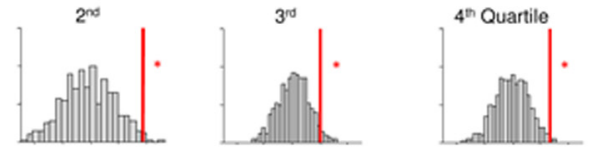

Dynamic range
D
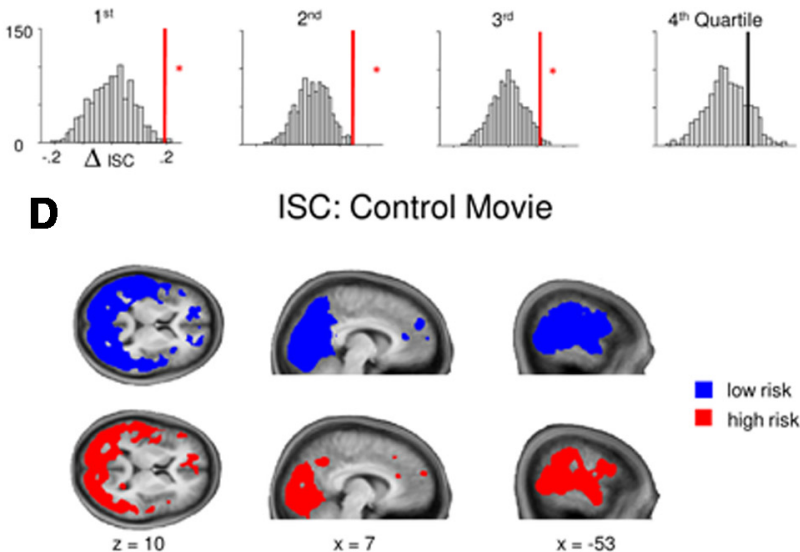

Figure 4. A, Nonparametric group permutation of ISC differences in regions of interest. Each viewer was randomly assigned to either the pseudo-high-risk or pseudo-low-risk group and ISC analysis was performed for each group. The plots represent the distribution of the ISC-group-difference $\left(I S C_{\text {high risk }}-I S C_{\text {low risk }}\right.$ ), computed using random groups. The red line represents the veridical ISC-group difference resulting when each viewer was assigned to the "true" groups based on individual perceptions of being at risk. As can be seen, nonparametric testing confirmed highly significant group differences for the pgACC and adMCC. By contrast, the obtained veridical ISC differences for the two sensory regions were low $(<0.1)$ and not significantly different between groups. $\boldsymbol{B}$, Nonparametric permutation tests conducted for the first, second, third, and fourth quartile of the 30 min long H1N1 documentary. $\boldsymbol{C}$, Comparison of the dynamic range of the fMRI responses. Time courses were sampled from the ROIs and SDs computed to quantify the amount of signal variation. Bars and error bars, mean and SD across observers. $\boldsymbol{D}$, ISC result maps during control stimulus viewing. Significantly correlated neural responses are present in widespread brain regions, extending far beyond primary sensory representation areas into higher-order cortex $(p<$ $\left.10^{-6}\right)$. Notably, the strength and regional distribution of correlated neural time courses was similar for both groups.

information unrelated to the risk domain. To conduct this test, all participants viewed a TV documentary about astronomy. Applying the same set of analyses to the processing of the control documentary, no significant group difference was observed (Fig. 4D).

\section{Overlap between interbrain (ISC) and intrabrain correlations (functional connectivity)}

The ISC result maps in Figure 2 represent similarities of processing in corresponding regions across different brains. This approach was complemented by functional connectivity, which reveals similarities of processing within the same brain (Friston, 1994; Raichle, 2011). Using seed coordinates derived from resting state studies (Seeley et al., 2007; Vincent et al., 2008; Burton et al., 2012), functional connectivity networks for vision, audition, as well as higher integrative networks related to default-mode, dorsal attention, executive control, and salience processing were identified (Seeley et al., 2007; Menon and Uddin, 2010; Raichle, 2011).

Plotting the functional network maps alongside the ISC maps (Fig. 5) reveals that the voxels exhibiting significant ISC substantially overlap the functional networks related to visual and auditory stimulus processing as well as the dorsal attention, default mode, and executive control network. This effect is seen for both high and low-H1N1 risk groups. The critical ACC group difference, however, coincides spatially with the so-called salience network, which contains key nodes in the AACC and bilateral insulae (Craig, 2002, 2009; Seeley et al., 2007; Menon and Uddin, 2010) Using a liberal threshold ( $p<0.001$, uncorrected, one-tailed) for exploratory purposes, we observed a broader spatial distribution of the ACC clusters in the high risk group, as well as additional group differences in regions of the anterior insulae and dorsolateral prefrontal, which often appears as a link between salience and cognitive and attentional control processing (Seeley et al., 2007; Shirer et al., 2012). In contrast, using the identical thresholds for the reverse ISC comparison $\left(\mathrm{ISC}_{\text {low risk }}>\mathrm{ISC}_{\text {high risk }}\right.$ ) showed no significant voxels.

\section{Discussion}

This study uses an innovative approach to study the reception of health-risk information: ISC analysis enabled us to examine the neural processing of a real-world TV report about H1N1. The main finding is that individuals with high versus low-H1N1 risk perception differed in the strength of intersubject correlations within the ACC, suggesting that receiver-sided differences in risk-perception covary with the processing of risk-related information in neural regions related to the personal evaluation of significant stimuli in the environment. Control analyses secured the findings with respect to statistical assumptions (nonparametric analyses), regional and temporal specificity (ROI-based analyses), and analytical confounds (response amplitude differences). Importantly, high and low H1N1 risk perception groups exhibited no neural differences when viewing a risk-neutral documentary about astronomy. From a broader perspective, these results suggest that ISC analysis is useful for studying neural correlates of 


\section{Functional connectivity networks and ISC result maps}

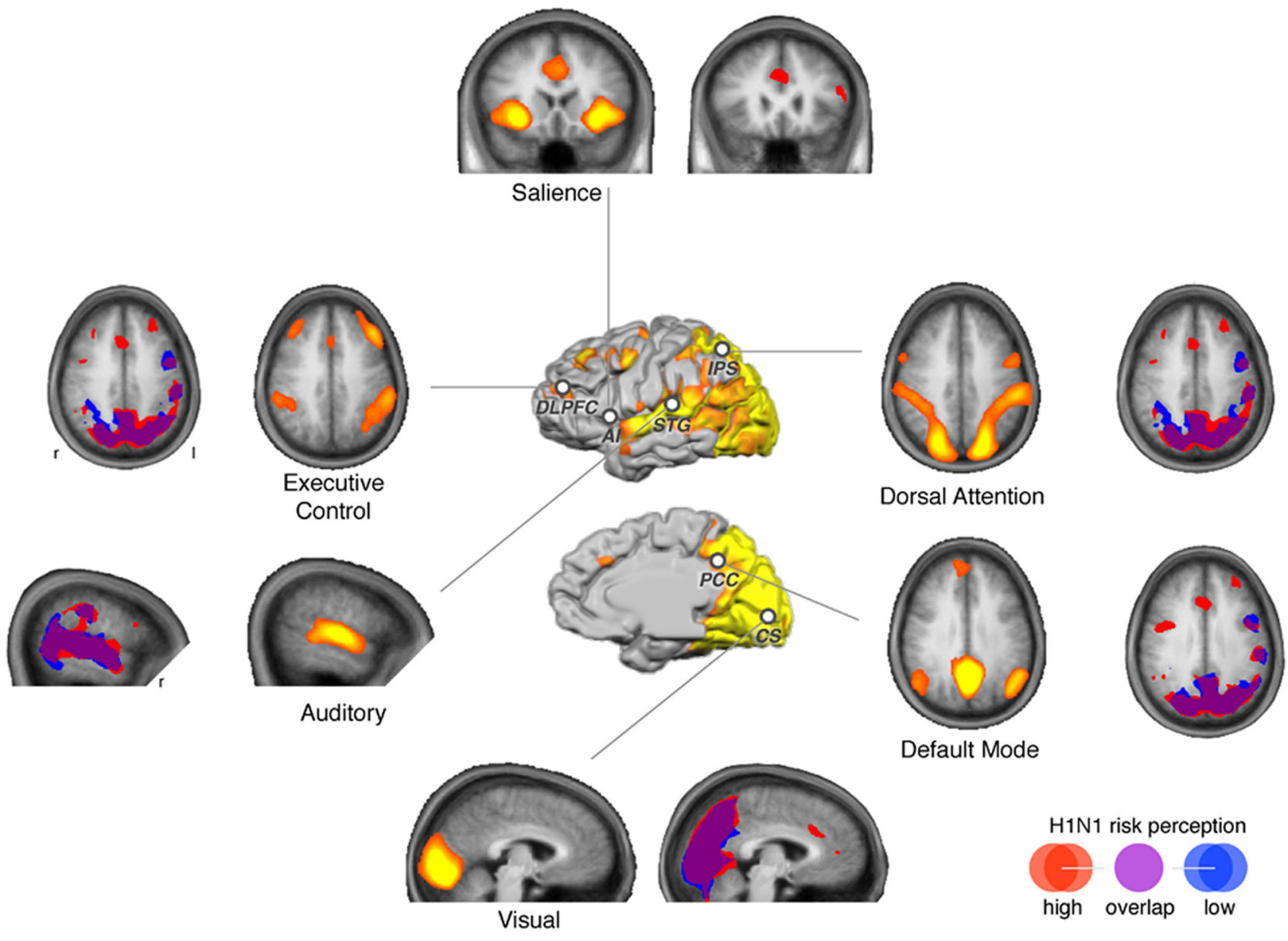

Figure 5. Overlap between major brain networks and ISC result maps. Circles indicate the seed regions for functional connectivity analysis. The resulting functional networks are presented side by side with the ISC maps for viewers with low (blue) and high (red) H1N1 risk perception, respectively. The ACC evinces more reliable responses among participants with a high H1N1 risk perception. Note, that differences in the thresholded ISC maps for each group do not constitute a formal statistical test of between-group differences (Fig. 3). Slice coordinates: Salience, $y=21$; executive control, $z=35$; default mode, $z=30$; visual, $x=-4$; auditory, $x=-53$; dorsal attention, $z=36$.

risk communication, particularly with respect to the role of emotion and differences in risk perceptions.

Previous studies on primates show that the ACC is connected with emotion-sensitive cortical and subcortical regions and acts as a hub for the greater limbic system (Paus, 2001; Vogt et al., 2004). Providing complementary data, reviews of functional imaging studies in humans relate the ACC to affective evaluation, evaluation of the meaning of external stimuli for the self, as well as to sympathetic activity and various emotional experiences (Schmitz and Johnson, 2007; Etkin et al., 2011; Shackman et al., 2011). The functional significance of the ACC effects was further revealed by examining the key words associated with the observed coordinates across the $\sim 4000$ studies included in the "Neurosynth" meta-analysis framework (Yarkoni et al., 2011). This showed that activity in the observed ACC regions is most strongly associated in the literature with terms, such as "emotion," "self," "pain," "negative," "positive," "reward," and "affective." Accordingly, the present results are considered to reflect the increased emotional significance of the H1N1 documentary in participants who are more worried and anxious about the H1N1 virus. Furthermore, Neurosynth coactivation maps as well as our functional connectivity analysis during naturalistic viewing, suggest functional links between the ACC and insular cortex, which comprise a network involved in the detection of salient stimuli (Seeley et al., 2007). Future studies should investigate the enhancement of ISC in the anterior insula that was seen at lower statistical thresholds and also examine possible effects for subcortical structures, particularly the amygdala and its subdivisions (Stein et al., 2007; Roy et al., 2009). Furthermore, the reported group differences during processing of the H1N1 documentary were observed with respect to an emotionally neutral movie featuring astronomy. To further examine the specificity of the ISC differences in the saliency network, future studies should extend the range of stimuli by examining responses for other types of risk and emotional control stimuli. More broadly, the present results demonstrate that ISC analysis can be used to test the connection between the neural systems that process risk-related and emotional information. Thus, a neuroscientific approach can inform and constrain models of risk processing such as the "risk as feelings" model (Loewenstein et al., 2001), which emphasizes the role of negative emotions, such as worry and anxiety in risk perceptions (Loewenstein et al., 2001; Slovic and Peters, 2006; Schmälzle et al., 2011, 2012; Renner et al., 2012).

Neuroscientific studies of anticipatory anxiety provide additional support for the role of emotions in risk perceptions (Etkin 
et al., 2011; Maier et al., 2012). Participants in these studies were verbally instructed that they might receive an electric shock when a particular cue was presented; a different cue signaled a safety period. Meta-analysis demonstrated that the processing of the threat cues was reliably associated with increased activation in dorsal ACC (Mechias et al., 2010). The current findings resonate with this line of research and suggest commonality with regard to the neural substrate. Specifically, exploratory analyses revealed increased ISC effects at the ACC coordinates identified by Maier et al. (2012) in connection with anticipatory anxiety. The processing of risk-related information and instructed fear signals include both the anticipation of future danger and harm for the self, which may be the common denominator for ACC effects. Thus, as proposed by the "risk as feelings" hypothesis, anticipatory anxiety may represent an integral aspect of acute risk perceptions (Renner and Reuter, 2012). However, there are important differences among both lines of research with respect to the imminence, personal experience, and concreteness of the anticipated threat, and so future studies systematically varying threat imminence will be informative. Overall, it is hypothesized that neural regions involved in anticipatory anxiety are also implicated in risk perception.

A crucial difference between the current study and prior work is that ACC function was previously assessed via peak signal changes ("activations") in response to discrete stimuli. In contrast, the current approach capitalizes on a region's temporal response profile during continuous real-life processing and assesses its correlation across individuals (Hasson et al., 2010). Differences between measures of response amplitude ("activations") and reliability ("correlations") have already been noted in previous studies (Hasson et al., 2008; Lerner et al., 2011; Ben-Yaakov et al., 2012; Pajula et al., 2012). For instance, disrupting the temporal order of a movie led to pronounced differences in response reliability but not amplitudes (measured as dynamic range of the signal), particularly in higher-order regions (Hasson et al., 2008). Similarly, in the current dataset there were no group differences in ACC in the dynamic range, but group differences emerged for the intersubject correlations. Thus, although the variability of neural time series (the height of peaks and troughs) is comparable, the temporal profiles seem more aligned across viewers with high as compared with low H1N1 risk perception. Accordingly, these findings provide further evidence for the sensitivity of the temporal profile of neural activity as compared with measures of aggregate activation in the processing of naturalistic stimuli.

Intersubject correlations of brain activity, when viewed from a communication-theoretic perspective, can be conceived as a neural counterpart of intersubjective agreement at the level of local brain processes, i.e., how similarly a particular region processes an incoming message across different individuals (Pickering and Garrod, 2004; Stephens et al., 2010; Littlejohn, 2002; cf. Hasson et al., 2012). A novel aspect of the present approach is that it extends ISC research to assess both neural commonalities and differences in the reception of risk communication, and thus can reveal "message main effects" (i.e., similar responses across all receivers) as well as "message-receiver interactions" (i.e., different responses in subgroups of receivers):

Regarding message main effects, we found very similar ISC maps for the low and high-risk perception groups in widespread regions of the posterior cortex (Fig. 2). The functional connectivity results (Fig. 5) further show that intersubjectively coupled brain processes are evoked in the visual and auditory systems, and overlap with the dorsal attention, default, and executive control networks. This suggests that regions in- volved in viewing, attending to, and extracting meaning from the $\mathrm{H} 1 \mathrm{~N} 1$ documentary were similarly engaged across viewers.

However, in addition to message main effects, we found enhanced ISC in the anterior cingulate among individuals with high-H1N1 risk perceptions (Fig. 3), indicative of an interaction between incoming information (TV report about $\mathrm{H} 1 \mathrm{~N} 1$ risk) and receiver characteristics (individual differences in $\mathrm{H} 1 \mathrm{~N} 1$ risk perception) in regions presumed to link external information (messages about H1N1) to evaluations of personal salience (Etkin et al., 2011; Roy et al., 2012) (e.g., "I am at risk"). This suggests that risk perceptions, which are commonly regarded as a prerequisite of protective health actions (Glik, 2007; Weinstein et al., 2007; Renner and Schupp, 2011), are critical for health communication because they may modulate how risk-related messages are processed.

Together, our results demonstrate that nonreactive neural measures hold much promise for assessing the effects of health risk communication. Previous studies revealed that neural responses to tailored health ads can predict individual health behaviors (Falk et al., 2010; Chua et al., 2011) and that "neural focus groups" may successfully predict the population-level impact of health messages (Falk et al., 2012). Within this context, the ISC approach presents a novel tool to assess the extent of shared neural processing evoked by real-life messages, providing a powerful and flexible framework for the neuroscientific study of mass communication in general and the communication of health information in particular (Falk, 2010). In addition to follow-up studies involving selected target risk groups and specific topical stimuli (e.g., smokers and smokingrelated messages), future studies may also vary the current approach, e.g., by identifying critical stimulus elements that enhance neural correlations (cf. Hasson et al., 2004), or by predicting agreement or disagreement regarding psychological phenomena (e.g., intentions for quitting, perceptions of risk, interpretations of symptoms) based on the similarity or dissimilarity of neural processing (cf. Kriegeskorte et al., 2008).

To conclude, our data offer new insights into how the brain processes risk-related information, showing that during the reception of real-life risk communication different preexisting risk perceptions are associated with ISC group differences in the ACC. Overall, the present approach reveals exciting research opportunities at the intersection of communication, health, and neuroscience.

\section{References}

Bartels A, Zeki S, Logothetis NK (2008) Natural vision reveals specialization to local motion and to contrast-invariant, global flow in the human brain. Cereb Cortex 18:705-717. CrossRef Medline

Benjamini Y, Hochberg Y (1995) Controlling the false discovery rate: a practical and powerful approach to multiple testing. J R Stat Soc Ser B 57:289-300.

Ben-Yakov A, Honey CJ, Lerner Y, Hasson U (2012) Loss of reliable temporal structure in event-related averaging of naturalistic stimuli. Neuroimage 63:501-506. CrossRef Medline

Boynton GM, Engel SA, Glover GH, Heeger DJ (1996) Linear systems analysis of fMRI in human V1. J Neurosci 16:4207-4221. Medline

Brennan J, Nir Y, Hasson U, Malach R, Heeger DJ, Pylkkanen L (2012) Syntactic structure building in the anterior temporal lobe during natural story listening. Brain Lang 120:163-173. CrossRef Medline

Brewer NT, Chapman GB, Gibbons FX, Gerrard M, McCaul KD, Weinstein ND (2007) Meta-analysis of the relationship between risk perception and health behavior: the example of vaccination. Health Psychol 26:136-145. CrossRef Medline

Burton H, Wineland A, Bhattacharya M, Nicklaus J, Garcia KS, Piccirillo JF 
(2012) Altered networks in bothersome tinnitus: a functional connectivity study. BMC Neurosci 13:3. CrossRef Medline

Cantlon JF, Li R (2013) Neural activity during natural viewing of Sesame Street statistically predicts test scores in early childhood. PLoS Biol 11: e1001462. CrossRef Medline

Chua HF, Ho SS, Jasinska AJ, Polk TA, Welsh RC, Liberzon I, Strecher VJ (2011) Self-related neural response to tailored smoking-cessation messages predicts quitting. Nat Neurosci 14:426-427. CrossRef Medline

Craig AD (2002) How do you feel? Interoception: the sense of the physiological condition of the body. Nat Rev Neurosci 3:655-666. CrossRef Medline

Craig AD (2009) How do you feel-now? The anterior insula and human awareness. Nat Rev Neurosci 10:59-70. CrossRef Medline

Etkin A, Egner T, Kalisch R (2011) Emotional processing in anterior cingulate and medial prefrontal cortex. Trends Cogn Sci 15:85-93. CrossRef Medline

Falk EB (2010) Communication neuroscience as a tool for health psychologists. Health Psychol 29:346-354. CrossRef Medline

Falk EB, Berkman ET, Mann T, Harrison B, Lieberman MD (2010) Predicting persuasion-induced behavior change from the brain. J Neurosci 30 : 8421-8424. CrossRef Medline

Falk EB, Berkman ET, Lieberman MD (2012) From neural responses to population behavior: neural focus group predicts population level media effects. Psychol Sci 23:439-445. CrossRef Medline

Friston KJ (1994) Functional and effective connectivity in neuroimaging: a synthesis. Hum Brain Map 2:56-78. CrossRef

Garrett DD, Kovacevic N, McIntosh AR, Grady CL (2011) The importance of being variable. J Neurosci 31:4496-4503. CrossRef Medline

Glik DC (2007) Risk communication for public health emergencies. Annual Rev Public Health 28:33-54. CrossRef Medline

Hasson U, Nir Y, Levy I, Fuhrmann G, Malach R (2004) Intersubject synchronization of cortical activity during natural vision. Science 303:16341640. CrossRef Medline

Hasson U, Yang E, Vallines I, Heeger DJ, Rubin N (2008) A hierarchy of temporal receptive windows in human cortex. J Neurosci 28:25392550. CrossRef Medline

Hasson U, Avidan G, Vallines I, Harel M, Minshew N, Behrmann M (2009) Shared and idiosyncratic cortical activation patterns in autism revealed under continuous real-life viewing conditions. Autism Res 2:220-231. CrossRef Medline

Hasson U, Malach R, Heeger DJ (2010) Reliability of cortical activity during natural stimulation. Trends Cogn Sci 14:40-48. CrossRef Medline

Hasson U, Ghazanfar AA, Galantucci B, Garrod S, Keysers C (2012) Brainto-brain coupling: a mechanism for creating and sharing a social world. Trends Cogn Sci 16:114-121. CrossRef Medline

Honey CJ, Thompson CR, Lerner Y, Hasson U (2012) Not lost in translation: neural responses shared across languages. J Neurosci 32:1527715283. CrossRef Medline

Kriegeskorte N, Mur M, Bandettini PA (2008) Representational similarity analysis-connecting the branches of systems neuroscience. Front Syst Neurosci 2:4. CrossRef Medline

Lacadie CM, Fulbright RK, Rajeevan N, Constable RT, Papademetris X (2008) More accurate Talairach coordinates for neuroimaging using nonlinear registration. Neuroimage 42:717-725. CrossRef Medline

Lerner Y, Honey, CJ, Silbert LJ, Hasson U (2011) Topographic mapping of a hierarchy of temporal receptive windows using a narrated story. J Neurosci 31:2906-2915. CrossRef Medline

Littlejohn, SW (2002) Theories of human communication. Belmont: Wadsworth.

Loewenstein GF, Weber EU, Hsee CK, Welch N (2001) Risk as feelings. Psychol Bull 127:67-86. CrossRef Medline

Maier S, Szalkowski A, Kamphausen S, Perlov E, Feige B, Blechert J, Philipsen A, Tebartz van Elst L, Kalisch R, Tuescher O (2012) Clarifying the role of the rostral dmPFC/dACC in fear/anxiety: learning, appraisal or expression? PLOS One, 7:e50120. CrossRef Medline

Mechias ML, Etkin A, Kalisch R (2010) A meta-analysis of instructed fear studies: implications for conscious appraisal of threat. Neuroimage 49: 1760-1768. CrossRef Medline

Menon V, Uddin LQ (2010) Saliency, switching, attention and control: a network model of insula function. Brain Struct Funct 214:655-667. CrossRef Medline
Mesulam MM (1998) From sensation to cognition. Brain 121:1013-1052. CrossRef Medline

Mukamel R, Gelbard H, Arieli A, Hasson U, Fried I, Malach R (2005) Coupling between neuronal firing, field potentials, and FMRI in human auditory cortex. Science 309:951-954. CrossRef Medline

Nir Y, Hasson U, Levy I, Yeshurun Y, Malach R (2006) Widespread functional connectivity and fMRI fluctuations in human visual cortex in the absence of visual stimulation. Neuroimage 30:1313-1324. CrossRef Medline

Pajula J, Kauppi JP, Tohka J (2012) Inter-subject correlation in fMRI: method validation against stimulus-model based analysis. PLoS ONE 7:e41196. CrossRef Medline

Paus T (2001) Primate anterior cingulate cortex: where motor control, drive and cognition interface. Nat Rev Neurosci 2:417-424. CrossRef Medline

Pickering MJ, Garrod S (2004) Toward a mechanistic psychology of dialogue. Behav Brain Sci 27:169-226. Medline

Pruessmann KP, Weiger M, Scheidegger MB, Boesiger P (1999) SENSE: sensitivity encoding for fast MRI. Magn Reson Med 42:952-962. CrossRef Medline

Raichle ME (2011) The restless brain. Brain Connect 1:3-12. CrossRef Medline

Renner B, Schupp HT (2011) The perception of health risk. In HS Friedman (ed), The Oxford handbook of health psychology. New York: Oxford UP.

Renner B, Reuter T (2012) Predicting vaccination using numerical and affective risk perceptions: the case of A/H1N1 influenza. Vaccine 30:70197026. CrossRef Medline

Renner B, Schmälzle R, Schupp HT (2012) First impressions of HIV risk: it takes only milliseconds to scan a stranger. PLoS One 7:e30460. CrossRef Medline

Roy AK, Shehzad Z, Margulis DS, Kelly AM, Uddin LQ, Gotimer K, Biswal BB, Castellanos FX, Milham MP (2009) Functional connectivity of the human amygdala using resting state fMRI. Neuroimage 145:614-626. CrossRef Medline

Roy M, Shohamy D, Wager TD (2012) Ventromedial prefrontal-subcortical systems and the generation of affective meaning. Trends Cogn Sci 16:147156. CrossRef Medline

Samanez-Larkin GR, Kuhnen CM, Yoo DJ, Knutson B (2010) Variability in nucleus accumbens activity mediates age-related suboptimal financial risk taking. J Neurosci 30:1426-1434. CrossRef Medline

Schmälzle R, Schupp HT, Barth A, Renner B (2011) Implicit and explicit processes in risk perception: neural antecedents of perceived HIV risk. Front Hum Neurosci 5:43. CrossRef Medline

Schmälzle R, Renner B, Schupp HT (2012) Neural correlates of perceived risk: the case of HIV. Soc Cogn Affect Neurosci 7:667-676. CrossRef Medline

Schmitz TW, Johnson SC (2007) Relevance to self: a brief review and framework of neural systems underlying appraisal. Neurosci Biobehav Rev 31: 585-596. CrossRef Medline

Seeley WW, Menon V, Schatzberg AF, Keller J, Glover GH, Kenna H, Reiss AL, Greicius MD (2007) Dissociable intrinsic connectivity networks for salience processing and executive control. J Neurosci 27:2349-2356. CrossRef Medline

Shackman AJ, Salomons TV, Slagter HA, Fox AS, Winter JJ, Davidson RJ (2011) The integration of negative affect, pain and cognitive control in the cingulate cortex. Nat Rev Neurosci 12:154-167. CrossRef Medline

Shirer WR, Ryali S, Rykhlevskaia E, Menon V, Greicius MD (2012) Decoding subject-driven cognitive states with whole-brain connectivity patterns. Cereb Cortex 22:158-165. CrossRef Medline

Slovic P, Peters E (2006) Risk perception and affect. Curr Direct Psychol Sci 15:322-325.

Stein MB, Simmons AN, Feinstein JS, Paulus MP (2007) Increased amygdala and insula activation during emotion processing in anxietyprone subjects. Am J Psychiatry 164:318-327. CrossRef Medline

Stephens JG, Silbert JL, Hasson U (2010) Speaker-listener neural coupling underlies successful communication. Proc Natl Acad Sci U S A 107: 14425-14430. CrossRef Medline

Talairach J, Tournoux P (1988) Co-planar stereotaxic atlas of the human brain. New York: Thieme Medical Publishers.

Vincent JL, Kahn I, Snyder AZ, Raichle ME, Buckner RL (2008) Evidence for a frontoparietal control system revealed by intrinsic functional connectivity. J Neurophysiol 100:3328-3342. CrossRef Medline 
Vogt BA, Hof PR, Vogt LJ (2004) Cingulate gyrus. In: G Paxino, JK Mai (eds), The human nervous system. Oxford: Academic.

Weinstein ND (2003) Exploring the links between risk perceptions and preventive health behavior. In J Suls, KA Wallston (eds), Social psychological foundations of health and illness, pp 22-53. Malden, MA: Blackwell.

Weinstein ND, Kwitel A, McCaul KD, Magnan RE, Gerrard M, Gibbons FX
(2007) Risk perceptions: assessment and relationship to influenza vaccination. Health Psychol 26:146-151. CrossRef Medline

Yarkoni T, Poldrack RA, Nichols TE, Van Essen DC, Wager TD. T.D (2011) Large-scale automated synthesis of human functional neuroimaging data. Nat Methods 8:665-670. CrossRef Medline 